\title{
Complicated delivery in a patient with acute respiratory distress syndrome on Coronavirus disease 2019 infection
}

\author{
Alexis Bikfalvi $^{1}$, Aleksandar Dabetic ${ }^{1}$, and Moira Robertson ${ }^{1}$ \\ ${ }^{1} \mathrm{CHUV}$
}

November 27, 2020

\begin{abstract}
A 39-year-old parturient contracted COVID-19 at 28 weeks of gestation and later developed ARDS requiring emergent caesarean section, intubation and 11 days of invasive ventilation. Her infant also required intubation due to hyaline membrane disease, he was not infected by COVID-19. Both evolved well and could return home.
\end{abstract}

\section{Hosted file}

Bikfalvi_november2020.pdf available at https://authorea.com/users/379298/articles/495525complicated-delivery-in-a-patient-with-acute-respiratory-distress-syndrome-oncoronavirus-disease-2019-infection

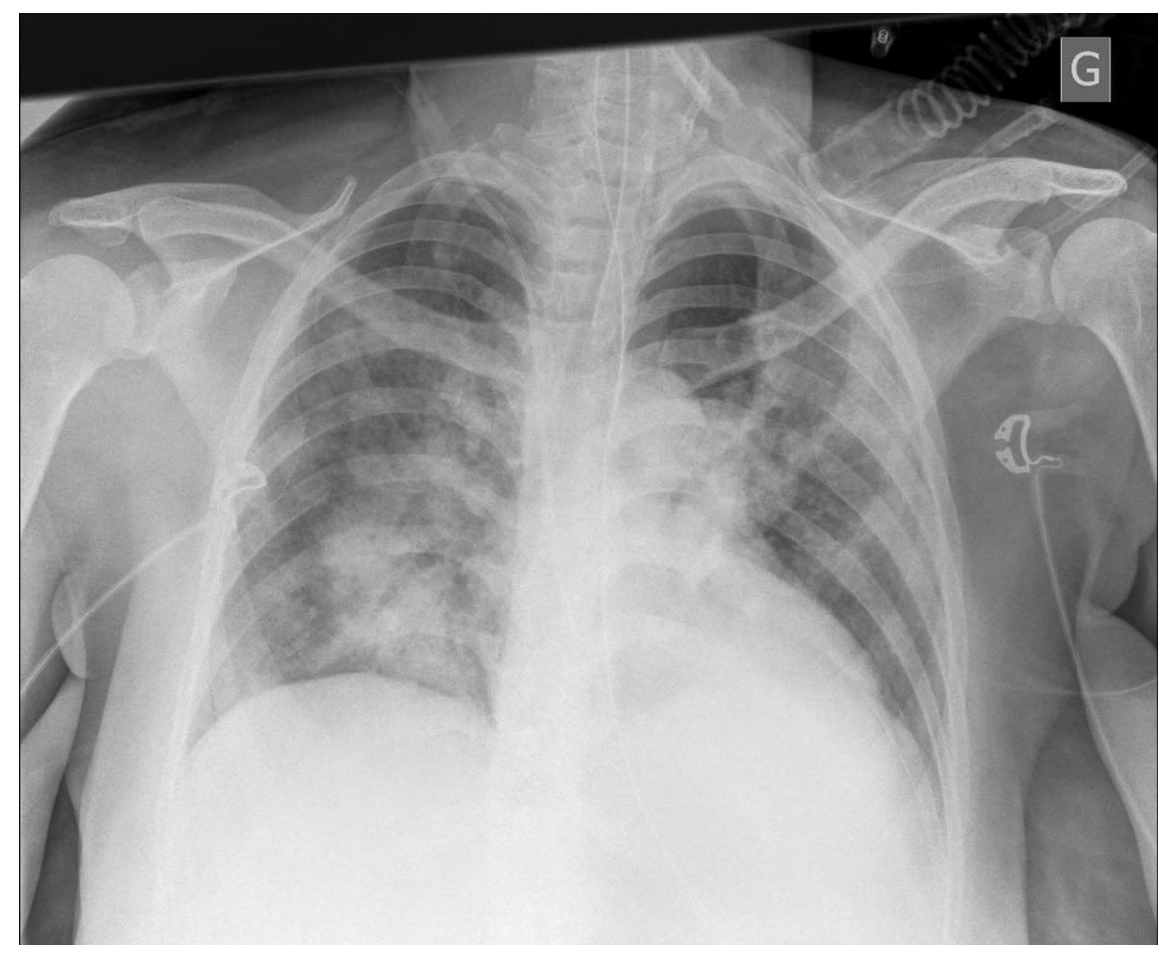




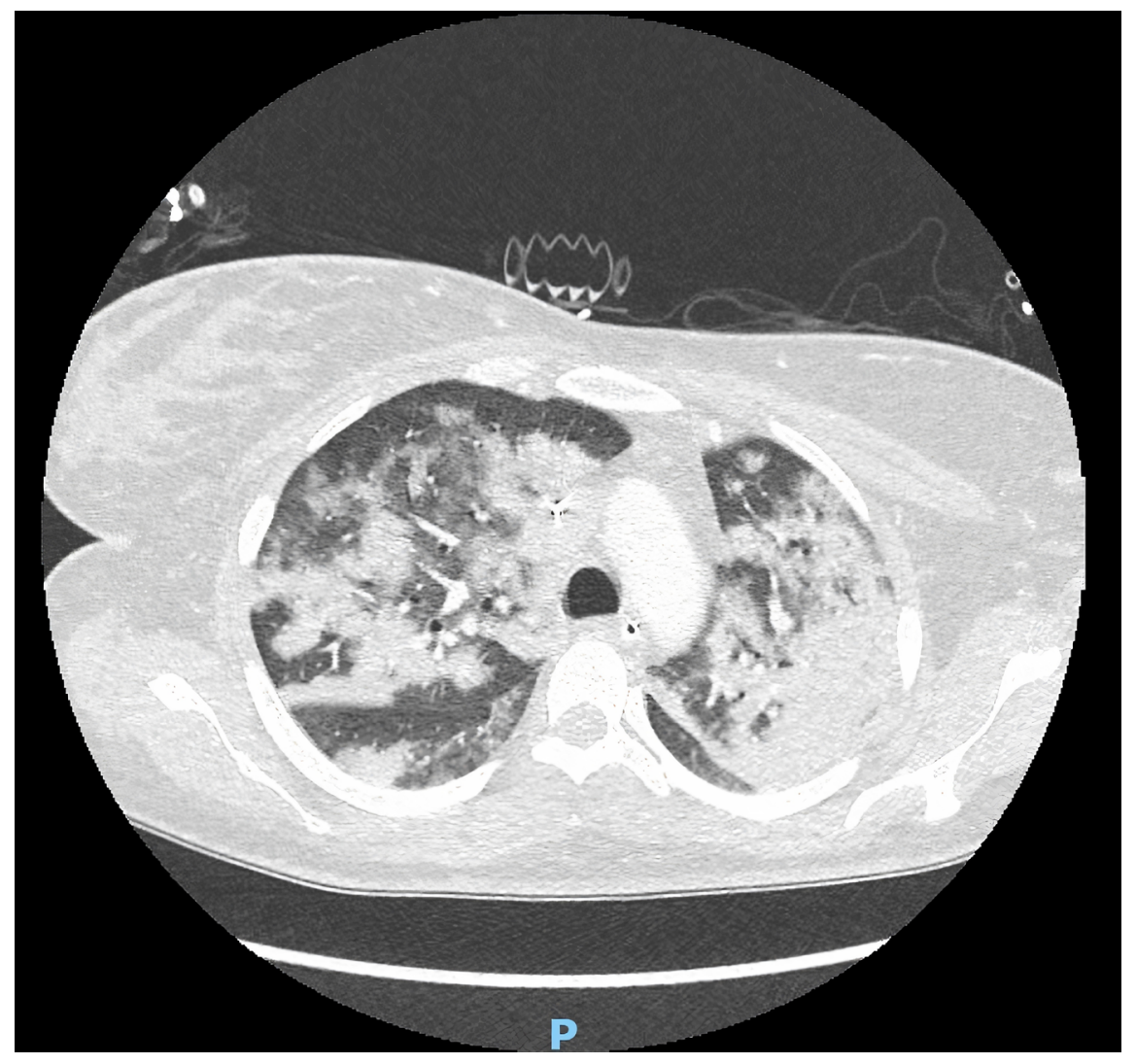

